\title{
Evaluation of digital thermography imaging to assess and monitor treatment of police working dogs with naturally occurring hip osteoarthritis
}

\author{
J. C. Alves ${ }^{1,2^{*}}\left(\mathbb{D}\right.$, A. Santos ${ }^{1}$, P. Jorge ${ }^{1}$, C. Lavrador ${ }^{2}$ and L. Miguel Carreira $3,4,5$
}

\begin{abstract}
Background: In dogs, thermal imaging has been documented only recently, but a growing interest in this modality has led to studies using thermography to assess pathologies in the canine hip, stifle, elbow, intervertebral disc, and bone neoplasia. This study aimed to evaluate the use of digital thermography in assessing and evaluating treatment response in dogs with hip osteoarthritis $(\mathrm{OA})$ and comparing its results with an objective measure and two clinical metrology instruments. In an experimental, randomized, double-blinded study, one hundred hip joints of fifty police working dogs with bilateral hip OA were evaluated. A dorsoventral and lateral thermographic image were obtained on days $0,8,15,30,90$, and 180. Mean and maximal temperatures were determined. Additionally, the animal's weight-bearing distribution and radiographic examination of the hip joint (extended legs ventrodorsal view) were performed. Copies of the Canine Brief Pain Inventory (CBPI) and Canine Orthopaedic Index (COI) were obtained. Results were analyzed by ANOVA, followed by an LSD post-hoc test, and correlations were assessed with Spearman correlation coefficient, with $p<0.05$.

Results: Values recorded on the lateral view were higher than those on the dorsoventral view. No differences or correlations were found between Orthopedic Foundation for Animals hip grades and temperature. Digital thermographic images showed a weak significant correlation with weight-bearing evaluations $(r=0.13, p<0.01)$ and different clinical metrology instruments scores $(r=-0.25, p<0.01$ for pain severity score, and $r=-0.21, p=0.04$ for gait). It also correlated with radiographic findings, specifically the circumferential femoral head osteophyte and caudolateral curvilinear osteophyte.
\end{abstract}

Conclusion: To our knowledge, this is the first study presenting the digital thermography assessment of Police working dogs submitted to treatment for hip OA. Digital thermography, mainly based on a lateral view evaluation, showed a weak significant correlation with stance analysis and clinical metrology instruments scores.

Keywords: Dog, Osteoarthritis, Hip, Digital thermography, Stance analysis, Clinical metrology instruments

\footnotetext{
*Correspondence: alves.jca@gnr.pt

'Divisão de Medicina Veterinária, Guarda Nacional Republicana (GNR), Rua Presidente Arriaga, 9, 1200-771 Lisbon, Portugal

${ }^{2}$ MED - Mediterranean Institute for Agriculture, Environment and

Development, Instituto de Investigação e Formação Avançada, Universidade de Évora, Pólo da Mitra, Ap. 94, 7006-554 Évora, Portugal

Full list of author information is available at the end of the article
}

(c) The Author(s). 2021 Open Access This article is licensed under a Creative Commons Attribution 4.0 International License, which permits use, sharing, adaptation, distribution and reproduction in any medium or format, as long as you give appropriate credit to the original author(s) and the source, provide a link to the Creative Commons licence, and indicate if changes were made. The images or other third party material in this article are included in the article's Creative Commons licence, unless indicated otherwise in a credit line to the material. If material is not included in the article's Creative Commons licence and your intended use is not permitted by statutory regulation or exceeds the permitted use, you will need to obtain permission directly from the copyright holder. To view a copy of this licence, visit http://creativecommons.org/licenses/by/4.0/. The Creative Commons Public Domain Dedication waiver (http://creativecommons.org/publicdomain/zero/1.0/) applies to the data made available in this article, unless otherwise stated in a credit line to the data. 


\section{Background}

Digital thermography is a contact-free, non-invasive screening tool that can assess soft tissue injuries, including muscle strains, sprains, tendinopathies, and OA in humans, horses, cats, and dogs [1-3]. It relies on identifying changes in heat in tissue due to disruptions of tissue morphology and physiological functions, which in turn relate to skin temperature control [4-6]. The rationale behind its use is that an injury is often associated with variations in blood flow on the affected site, changing the skin temperature [7]. Changes in blood flow rate, local structures of subcutaneous tissues, and the sympathetic nervous system's activity are reflected on skin temperature through a complex system [1]. Inflammation in subcutaneous and deeper tissues reflects temperature changes in superficial tissues. These changes are a product of the inflammation mechanism, which influences blood vessels' diameter, blood flow rate, and capillary permeability [8, 9]. Digital thermography can provide a reproducible screening tool by describing the specific changes in each disease process $[10,11]$. It has been described as useful in humans, horses, and cats $[1,3,12,13]$. There has been a growing interest in thermal imaging in dogs, with recent reports on thermography use to assess pathologies in the canine hip, stifle, elbow, intervertebral disc, and bone neoplasia published [2, 13-18]. These studies have described normal thermal imaging of different body areas or diseases. Still, there are no studies available to our knowledge comparing the results of thermal imaging with other evaluation modalities and in the evaluation of response to treatment.

OA is the most prevalent joint disease in dogs, with an estimated prevalence of 20\% [19-22]. Since the disease lacks obvious extra-articular manifestations, it is well suited to use a local therapy by intra-articular (IA) injection [23]. Commonly used IA treatment modalities include corticosteroids (as triamcinolone hexacetonide), hyaluronan, and autologous platelets [24-26]. Pain is the most relevant clinical sign of $\mathrm{OA}$ and a hallmark of the disease [27, 28]. Several clinical metrology instruments have been developed to assess pain and evaluate treatment response [29]. One of the best clinical metrology instrument created for dogs is the Canine Brief Pain Inventory (CBPI), divided into a pain severity score (PSS), to evaluate the overall pain magnitude and a pain interference score (PIS), to assesses the degree to which pain affects daily activities [30-34]. The Canine Orthopaedic Index (COI) is an additional clinical metrology instrument to evaluate other dimensions of OA's impact. It is divided into stiffness, gait, function, and quality of life scores [35-38]. A typical assessment performed during the orthopedic examination is evaluating weight distribution, off-loading, or limb favoring at the stance [39].
OA patients exhibit subtle shifts in body weight distribution at a stance due to pain or instability [40, 41]. Stance analysis, which evaluates individual limb weight-bearing, is an objective measure, reported as sensitive for detecting lameness in dogs [41], and equivalent or superior measurement of hip OA-related pain associated with hip OA than vertical impulse and peak vertical force [41].

This study aimed to evaluate the use of digital thermography in assessing and evaluating treatment response in dogs with hip OA. As OA is a disease involving multiple dimensions, from changes in limb function, ability to conduct daily activities, and demeanor [32], we also aimed to compare the results of digital thermography to an objective measure (weight-bearing evaluation) and two clinical metrology instruments (the CBPI and the COI). We hypothesize that digital thermography results will correlate with the weight-bearing assessment results, the considered clinical metrology instruments, and radiographic examination.

\section{Results}

The sample from this study included 100 limbs of 50 Police working dogs with bilateral hip OA: 17 German Shepherd Dogs, 15 Belgian Malinois Shepherd Dogs, 10 Labrador Retriever, and 8 Dutch Shepherd Dog, 30 from males and 20 females, with a mean age of $6.5 \pm 2.2$ years, bodyweight of $26.7 \pm 5.3 \mathrm{~kg}$ and body condition score of $4 / 9$ [42]. Joints were classified as mild $(n=70)$, moderate (20), and severe (10), according to the Orthopedic Foundation for Animals hip grading scheme [43, 44]. Three images (1 DV and $2 \mathrm{LT}$, to have a DV and LT view from each joint) were obtained from each animal in six different evaluation moments (days $0,8,15,30,90$, and 180), amounting to 900 images. All patients were followed up to the last evaluation day. At the initial evaluation (day $0)$, the mean and maximal temperature on the DV were $24.7^{\circ} \mathrm{C} \pm 1.7$ and $25.8^{\circ} \mathrm{C} \pm 1.7$, respectively. On the LT view, mean and maximal temperatures were $26.1^{\circ} \mathrm{C} \pm 2.3$ and $28.1{ }^{\circ} \mathrm{C} \pm 2.4$, respectively. The thermographic evaluation results in each view by the Orthopedic Foundation for Animals hip grades are presented in Table 1. No significant differences or correlations were found between OFA hip grade and temperature.

Table 1 Mean and maximal thermographic evaluation values ( \pm standard deviation) of ventrodorsal and lateral views, by Orthopedic Foundation for Animals hip grades at the initial evaluation

\begin{tabular}{|c|c|c|c|c|}
\hline \multirow[t]{3}{*}{ OFA hip grade } & \multirow{2}{*}{\multicolumn{2}{|c|}{$\begin{array}{l}\text { Dorsoventral view } \\
\left({ }^{\circ} \mathrm{C}, \text { mean } \pm \mathrm{SD}\right)\end{array}$}} & \multirow{2}{*}{\multicolumn{2}{|c|}{$\begin{array}{l}\text { Lateral view } \\
\left({ }^{\circ} \mathrm{C}, \text { mean } \pm \mathrm{SD}\right)\end{array}$}} \\
\hline & & & & \\
\hline & Mean & Max & Mean & Max \\
\hline Mild $(n=70)$ & $24.9 \pm 1.6$ & $25.9 \pm 1.6$ & $26.2 \pm 2.2$ & $28.2 \pm 2.1$ \\
\hline Moderate $(n=20)$ & $24.9 \pm 1.8$ & $25.9 \pm 1.9$ & $26.1 \pm 2.6$ & $28.2 \pm 2.4$ \\
\hline Severe $(n=10)$ & $24.0 \pm 1.8$ & $25.0 \pm 1.7$ & $25.5 \pm 2.6$ & $27.2 \pm 2.3$ \\
\hline
\end{tabular}


Mean and maximal values of ventrodorsal and lateral views on each evaluation day are presented in Table 2 . Compared to the initial evaluation, significant variations in the thermographic evaluation were recorded mainly on the lateral view. During follow-up evaluations, significant differences in the result of treatment were registered with SI $(p<0.01)$ and deviation $(p<0.01)$. Correlations between thermography evaluation and weight-bearing evaluation, on the initial assessment and during the follow-up period, are presented in Table 3. Correlations between thermography evaluation and clinical metrology instrument scores on the first assessment and during the follow-up period are shown in Table 4. Considering radiographic findings, at the initial evaluation, maximal DV, mean and maximal LT thermographic evaluations showed a weak correlation with the presence of caudolateral curvilinear osteophyte on the ventrodorsal view $(r=-0.2, p=0.05 ; r=-0.3, p<0.01$ and $r=-0.2, p=0.04$, respectively).

\section{Discussion}

Digital thermal imaging can be used to assess musculoskeletal conditions, including OA, based on the variations in blood flow that injury and inflammation generate, which can affect the skin temperature [7-9]. To our knowledge, this is the first study to describe the use of digital thermography in the initial evaluation and to monitor treatment outcome in dogs with OA.

Pain is the most relevant clinical sign of OA [27, 28], and it is a multi-dimensional experience with functional, sensory, evaluative, and affective components [45]. To capture information regarding this wide-ranging nature of the disease, we choose to compare digital thermography to an objective measure, stance analysis [41], directed at evaluating the function, and two different clinical metrology instruments, to assess pain and the ability to conduct specific daily activities. Previous reports indicate that SI is reliable indicators of clinical

Table 2 Mean and maximal thermographic evaluation temperature values ( \pm standard deviation) of ventrodorsal and lateral views, on each evaluation moment. * indicates significant differences when compared with day 0 evaluation $(p<0.01)$. Negative values represent negative correlations between values

\begin{tabular}{|c|c|c|c|c|}
\hline \multirow[t]{3}{*}{ Instant } & \multicolumn{2}{|c|}{ Dorsoventral view } & \multicolumn{2}{|c|}{ Lateral view } \\
\hline & \multicolumn{2}{|c|}{$\left({ }^{\circ} \mathrm{C}\right.$, mean $\left.\pm \mathrm{SD}\right)$} & \multicolumn{2}{|c|}{$\left({ }^{\circ} \mathrm{C}\right.$, mean $\left.\pm \mathrm{SD}\right)$} \\
\hline & Mean & Max & Mean & Max \\
\hline 0 & $24.9 \pm 1.7$ & $25.8 \pm 1.7$ & $26.1 \pm 2.3^{*}$ & $28.1 \pm 2.4^{*}$ \\
\hline 8 & $24.0 \pm 2.3$ & $25.5 \pm 2.2$ & $30.9 \pm 2.3^{*}$ & $34.6 \pm 1.6^{*}$ \\
\hline 15 & $26.6 \pm 2.2$ & $25.9 \pm 2.3$ & $29.5 \pm 3.1^{*}$ & $34.3 \pm 1.6^{*}$ \\
\hline 30 & $24.8 \pm 2.3$ & $26.3 \pm 2.3$ & $29.6 \pm 2.6^{*}$ & $33.6 \pm 1.9^{*}$ \\
\hline 90 & $25.8 \pm 1.3$ & $27.1 \pm 1.4^{*}$ & $28.5 \pm 2.1^{*}$ & $30.7 \pm 2.3^{*}$ \\
\hline 180 & $25.5 \pm 1.3$ & $26.9 \pm 1.2^{*}$ & $28.2 \pm 2.1^{*}$ & $30.6 \pm 2.1^{*}$ \\
\hline
\end{tabular}

Table 3 Correlation coefficients between thermography evaluation and weight-bearing evaluation (symmetry index and deviation from the normal 20\% weight-bearing), on the initial evaluation and during the follow-up period. COI - Canine Orthopedic Index; PIS - Pain Interference Score; PSS - Pain Severity Score; QOL - Quality of Life; SI - Symmetry Index. ${ }^{a}$ indicates a significant correlation

\begin{tabular}{|c|c|c|c|c|c|}
\hline \multirow{2}{*}{ Measure } & & \multicolumn{2}{|c|}{ Initial evaluation } & \multicolumn{2}{|c|}{ Follow up period } \\
\hline & & SI & Deviation & SI & Deviation \\
\hline \multirow[t]{2}{*}{ Dorsoventral mean } & $r_{s}$ & 0.22 & 0.06 & -0.05 & -0.03 \\
\hline & Sig. & 0.83 & 0.59 & 0.27 & 0.49 \\
\hline \multirow[t]{2}{*}{ Dorsoventral max } & $r_{s}$ & 0.48 & 0.04 & -0.12 & -0.05 \\
\hline & Sig. & 0.65 & 0.73 & $0.01^{a}$ & 0.27 \\
\hline \multirow[t]{2}{*}{ Lateral mean } & $r_{s}$ & 0.04 & 0.05 & 0.08 & 0.09 \\
\hline & Sig. & 0.97 & 0.65 & 0.08 & $0.04^{\mathrm{a}}$ \\
\hline \multirow[t]{2}{*}{ Lateral max } & $r_{s}$ & 0.03 & 0.07 & 0.13 & 0.10 \\
\hline & Sig. & 0.75 & 0.51 & $<0.01^{\mathrm{a}}$ & $0.04^{a}$ \\
\hline
\end{tabular}

lameness in dogs [46]. Considering a cut-off point of $18 \%$ of weight-bearing for pelvic limbs seems to increase sensitivity and specificity [41, 47, 48]. For that reason, we compared thermography scores with both SI and deviation from the normal value of $20 \%$. During the follow-up period, digital thermography results based on the lateral view, specifically the maximal value, showed low but significant correlations with stance analysis results, which provides evidence favoring using a lateral view rather than a dorsoventral when monitoring OA treatment. Still, the dorsoventral maximal value also showed a week significant correlation with SI. This is not entirely unexpected, as inflammatory mediators drive OA within the joint, and thermography has shown to be a reliable technique to assess inflammatory pain and differentiate normal from human osteoarthritis patients [49-51]. The use of the maximal temperature value may better reflect this inflammatory process and nature. It may also present an additional advantage for less experienced operators than mean values. This last approach requires a more precise determination of anatomical areas of interest and is influenced by incorrect inclusion of measurements from non-affected tissues. It is also well established that the perception of pain and overall joint function is influenced by sensory innervation of the tissues that compose the joint, from the subchondral bone, periosteum, synovium to the capsule, and surrounding tissues, such as muscles [52, 53]. As LT views include a more significant amount of muscle masses than DV views, which are also involved in the disease process and under inflammation, this may account for higher mean and maximal temperature values registered on a lateral view $[51,54]$. It may also account for the weak significant correlation between LT evaluations and pain severity scores during the follow-up 
Table 4 Correlation coefficients between thermography evaluation and clinical metrology instrument scores, on the initial evaluation and during the follow-up period. COI - Canine Orthopedic Index; PIS - Pain Interference Score; PSS - Pain Severity Score; QOL - Quality of Life; SI - Symmetry Index. ${ }^{\mathrm{a}}$ indicates a significant correlation

\begin{tabular}{|c|c|c|c|c|c|c|c|c|c|}
\hline \multirow{2}{*}{$\begin{array}{l}\text { Evaluation } \\
\text { moment }\end{array}$} & \multirow[t]{2}{*}{ Measure } & & \multicolumn{7}{|l|}{ Score } \\
\hline & & & PSS & PIS & $\mathrm{COI}$ & Stiffness & Function & Gait & QOL \\
\hline \multirow[t]{8}{*}{ TO } & Dorsoventral mean & $r_{s}$ & -0.01 & -0.03 & -016 & -0.21 & -0.11 & -0.22 & -0.03 \\
\hline & & Sig. & 0.89 & 0.78 & 0.13 & $0.04^{\mathrm{a}}$ & 0.28 & $0.04^{\mathrm{a}}$ & 0.78 \\
\hline & Dorsoventral maximal & $r_{s}$ & $-0,02$ & -0.03 & -0.14 & -0.17 & -0.11 & -0.19 & -0.01 \\
\hline & & Sig. & 0.89 & 0.81 & 0.19 & 0.10 & 0.31 & 0.06 & 0.97 \\
\hline & Lateral mean & $r_{s}$ & -0.04 & -0.06 & -0.12 & -0.10 & -0.41 & -0.21 & -0.02 \\
\hline & & Sig. & 0.73 & 0.59 & 0.28 & 0.32 & 0.69 & $0.04^{\mathrm{a}}$ & 0.84 \\
\hline & Lateral maximal & $r_{s}$ & -0.01 & -0.01 & -0.09 & -0.84 & -0.07 & -0.17 & 0.03 \\
\hline & & Sig. & 0.99 & 0.98 & 0.36 & 0.42 & 0.48 & 0.09 & 0.81 \\
\hline \multirow[t]{8}{*}{ Follow up period } & Dorsoventral mean & $r_{s}$ & -0.04 & -0.04 & -0.06 & -0.05 & -0.04 & -0.06 & -0.07 \\
\hline & & Sig. & 0.42 & 0.36 & 0.25 & 0.32 & 0.38 & 0.23 & 0.16 \\
\hline & Dorsoventral maximal & $r_{s}$ & 0.06 & -0.01 & -0.01 & 0.02 & 0.01 & -0.06 & -0.01 \\
\hline & & Sig. & 0.23 & 0.91 & 0.77 & 0.70 & 0.91 & 0.22 & 0.97 \\
\hline & Lateral mean & $r_{s}$ & -0.10 & -0.01 & 0.04 & 0.03 & 0.06 & 0.01 & 0.08 \\
\hline & & Sig. & $0.03^{\mathrm{a}}$ & 0.82 & 0.37 & 0.59 & 0.22 & 0.79 & 0.08 \\
\hline & Lateral maximal & $r_{s}$ & -0.25 & -0.06 & -0.01 & -0.01 & -0.01 & -0.1 & 0.3 \\
\hline & & Sig. & $<0.01^{\mathrm{a}}$ & 0.22 & 0.94 & 0.86 & 0.79 & 0.79 & 0.5 \\
\hline
\end{tabular}

evaluations. An additional reason for these weak but significant correlations (also reflected in the scatter plot) may be related to the fact that different evaluation methods are capturing different dimensions of OA [32].

The thermographic evaluation also correlated with clinical metrology instruments scores, specifically gait and function, at the initial assessment. This can be explained by the fact that inflammation, whose effect is recorded by digital thermography, reflects affected tissues, their contribution to pain perception, and loss of normal function. These signs, related to an inability to perform normal daily activities, are most likely to present a patient for consultation [29]. As most joints represented in this sample were classified as mild OA, they are likely expressed mainly on scores that aim to measure functionality rather than overall demeanor, such as QOL. A weak significant correlation was observed with the PSS, but not with PIS, and only during the follow-up period. This is not entirely unexpected, as patients in this study high-drive working dogs, which tend to be stoic and usually show only subtle signs of pain, making its evaluation more challenging $[55,56]$.

In a human OA study, increased temperatures have been related to even slight degenerative changes and low temperatures with more severe disease cases [9]. In other reports, a correlation between increasing temperature and more severe radiographic changes has been described $[57,58]$. Although no differences were found in the thermographic evaluation of different OFA hip grades, hip joints classified as severe did have lower values in all considered thermographic evaluations, which may signal a trend. With severe OA, a loss of the tissues that surround the joint also occurs $[1,51]$. These factors may be responsible for the decrease in temperature observed in severe hip grades than moderate hip grades. The evaluation of more hips classified as severe would help clarify this fact, as the large majority of joints considered in this study were classified as mild. The circumferential femoral head osteophyte and the caudolateral curvilinear osteophyte are the two features that represent early radiographic signs that predict the development of the clinical symptoms of hip OA [43, 59-61]. This is supported by our results, as both showed a correlation with digital thermography evaluation and may be linked to the inflammatory process that drives $\mathrm{OA}$ and is responsible for producing clinical signs.

This study evaluated digital thermography's ability to assess and assess treatment response in dogs with hip OA by comparing digital thermography results with other commonly used and validated evaluation modalities. A limitation of the study is related to the fact that evaluated dogs were working dogs, which tend to be stoic, making it more challenging to assess these patients using the CBPI $[55,56]$. Also, the majority of animals had mild or moderate OA. It would be of interest to include disease-free patients and a larger proportion of animals representing the remaining hip grades to describe their digital thermography evaluation and this evaluation technique's ability to differentiate between them. 


\section{Conclusions}

To our knowledge, this is the first study presenting the digital thermography assessment of Police working dogs submitted to treatment for hip OA. Significant variations were observed in the thermographic evaluation of patients between initial and follow-up evaluations. Digital thermography, mainly based on an LT view evaluation, correlated with weight-bearing distribution and clinical metrology instruments scores. It also correlated with the presence of caudolateral curvilinear osteophyte on the ventrodorsal view at the initial assessment, a finding associated with the development of clinical symptoms of hip OA. Digital thermography may be an option for the screening of dogs with hip OA.

\section{Methods}

The sample comprised one hundred $(N=100)$ hip joints from fifty active police working dogs with naturally occurring bilateral hip OA, constituting a convenience sample of patients presenting for treatment in the Clinica Veterinária de Cães of the Guarda Nacional Republicana (Portuguese Gendarmerie), after they were first diagnosed. All patients were active working dogs and remained in active work during and after this study's conclusion. For this report, data from a longitudinal double-blinded, negative controlled study was used. Animals were signaled based on a diagnosis consistent with bilateral hip OA. For the diagnosis, the dog's history was considered, in addition to a difficulty to perform specific exercises (as rising, jumping, or maintaining obedience positions, leading to a worse performance), a physical examination consistent with hip OA (joint pain and stiffness, with a reduced range of motion), and an OFA hip scores of mild, moderate or severe. Additionally, they should be over 2 years and have a bodyweight $\geq 20 \mathrm{~kg}[62,63]$. They could not be on any medication or nutritional supplements for 6 weeks or more to allow a washout period [64]. Animals with any other suspected or documented orthopedic, neurological, or concomitant disease were excluded. Other conditions were ruled out through physical and radiographic examination, complete blood count, and serum biochemistry. The same researcher examined all patients.

Using a statistical analysis software, patients were randomly assigned to a group and, on day 0 (treatment day), either received an intra-articular administration of $0.9 \% \mathrm{NaCl}$ (control group) or treatment (a platelet concentrate - VPET ${ }^{\oplus}$, Hylan G-F 20, stanozolol or triamcinolone hexacetonide), the same to both hips, according to the assigned group. All groups had the same number of joints $(n=20)$, and all administrations were performed by the same researcher, blinded to the given group. No other medications/treatments were administered during the follow-up period.

Thermographic images, CBPI, COI, and weight-bearing evaluation results were recorded on days $0,8,15,30,90$, and 180, corresponding to the day when the IA treatment response was evaluated. These evaluations were conducted before the IA administration. On each assessment, three images were taken sequentially: a dorsoventral view, a right lateral view, and a left lateral view, with a FLIR ThermaCAM E $25^{\circ}$ camera. A single researcher, blinded to the patient's assigned group, performed the thermographic evaluation. Before image collection, dogs were introduced in a room with a controlled temperature, set at $21^{\circ} \mathrm{C}$. They were allowed to walk calmly to adjust to room temperature for $30 \mathrm{~min}$. During the actual image collection, animals were positioned standing in an upright position, as symmetrically as possible. When required, the dog's trainer assisted in maintaining the animal's position. They were allowed to touch the dog's abdomen but not its torso. Each dorsoventral image included the last lumbar vertebra area to the first coccygeal vertebra (Fig. 1). This procedure has high repeatability between observers and cameras [13]. For the lateral views, the greater trochanter was located and placed in the image's center (Fig. 2).

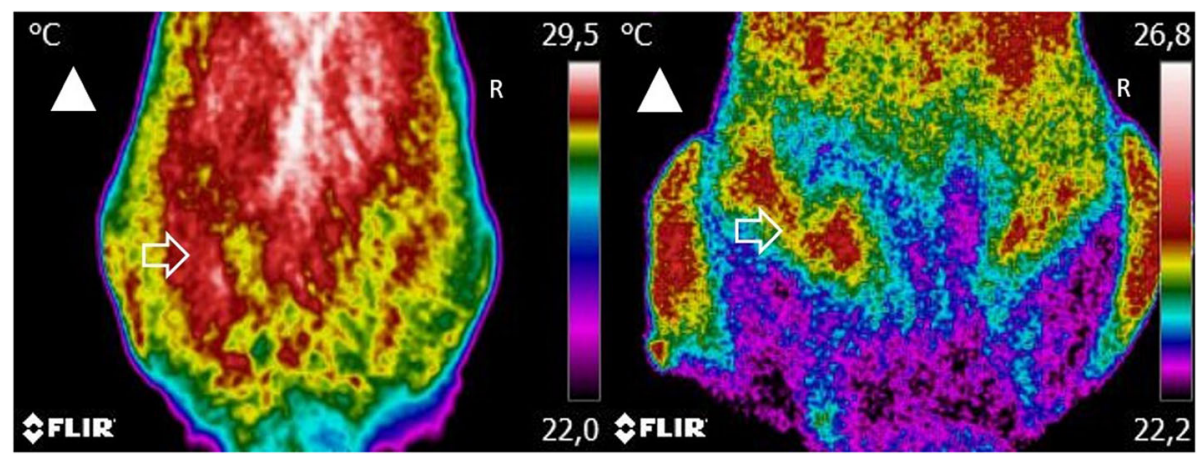

Fig. 1 A dorsoventral view of two dogs with moderate (left) and severe (right) osteoarthritis. Images include the area from the last lumbar vertebra to the first coccygeal vertebra at a minimum, at a distance of $60 \mathrm{~cm}$. Arrowhead indicates the direction of the dog's head. Arrow indicates the anatomical location of the hip joint. Increased temperature areas are observed on the hip joint, but with surrounding lower temperatures on the patient with severe OA 


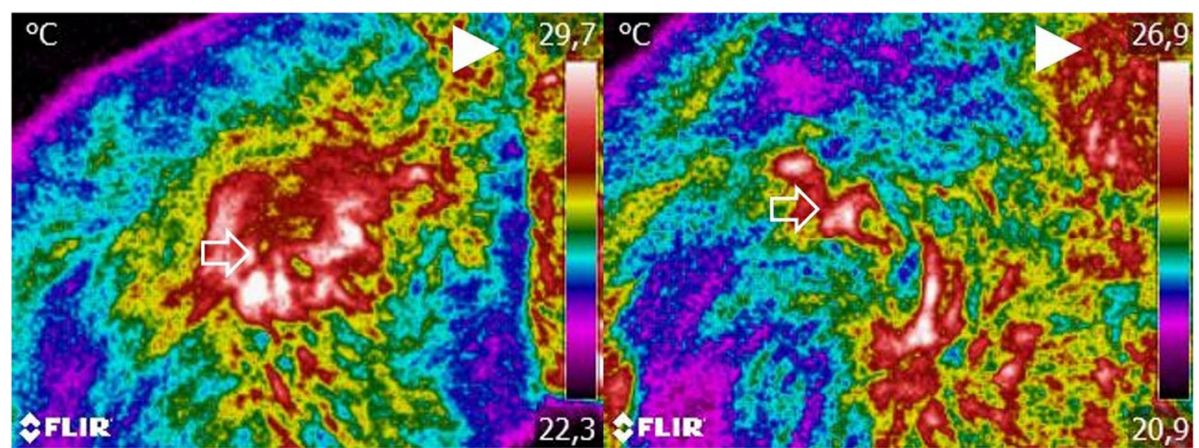

Fig. 2 A dorsoventral view of the same two dogs represented in Fig. 1, with moderate (left) and severe (right) osteoarthritis. Images were taken with the greater trochanter in the center of the image at a distance of $60 \mathrm{~cm}$. Arrowhead the direction of the dog's head. Arrow indicates the anatomical location of the hip joint. Increased temperature areas are observed on the hip joint, but with surrounding lower temperatures on the patient with severe OA

Figure 3 shows a dog at the time of initial evaluation and 30 days post-treatment. No fur clipping was performed before image collection since it can be harmful for thermographic evaluation, affecting reading stability for at least $60 \mathrm{~min}$ after clipping [14]. Image settings were adjusted to include a range of $15-40^{\circ} \mathrm{C}$ and emissivity of 0.98. Thermographic images were analyzed with Tools (FLIR Systems, Inc), a Rainbow HC color pallet was selected, and equal-sized temperature boxes were placed on the hip joint's anatomical area. Mean and maximal temperatures were determined.

After image collection, handlers received the published instructions for CBPI and COI and completed an online copy of each for them. These were completed in sequence by the same handler, which was blinded to the group his/ her dog was assigned, in each of the follow-up assessments, without knowledge of their previous answer. Weightbearing distribution was obtained with the Companion Stance Analyzer (LiteCure LLC, Newark, Delaware, United States). The equipment was placed on a flat surface in the center of a room, at least $1 \mathrm{~m}$ from the walls, calibrated at the beginning of each day, and zeroed before each evaluation moment. Animals were encouraged by their handlers to stand on to the weight distribution platform, with one foot on each quadrant. Gentle restraint was used to maintain the patient's head in a natural, forward-facing position. For each patient, 20 measurements were conducted, and a mean value was obtained. Normal weight distribution for each limb is considered $20 \%$ of the total weight [41], and we also considered the deviation from this value, obtained by subtracting the weight-bearing of the limb to 20 . Additionally, a left-right symmetry index (SI) was calculated, using the following formula: $\mathrm{SI}=\left[\left(\mathrm{WB}_{\mathrm{R}}-\mathrm{WB}_{\mathrm{L}}\right) /\right.$ $\left.\left(\left(W_{B}+W_{B}\right) \times 0.5\right)\right] \times 100 \quad\left(W_{R}=\right.$ weight-bearing of the right pelvic limb and $\mathrm{WB}_{\mathrm{L}}=$ weight-bearing for the left pelvic limb) [32, 65]. Negative symmetry index values were transformed to positive values. Radiographic images were conducted under light sedation, using a combination of medetomidine $(0.01 \mathrm{mg} / \mathrm{kg})$ and buthorphanol $(0.1 \mathrm{mg} / \mathrm{kg})$, given intravenously. A ventrodorsal extended view was obtained, as described elsewhere [43]. Since sedation can influence blood circulation and body temperature, this

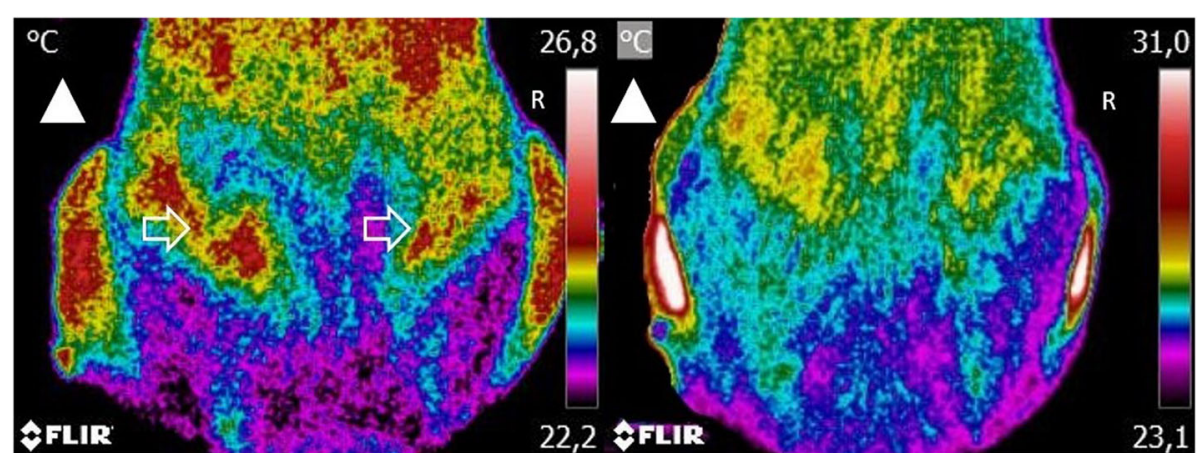

Fig. 3 A dorsoventral view of the same dog at the time of initial evaluation (left) and 30-days post-treatment (right). Arrowhead the direction of the dog's head. Arrow indicates the anatomical location of the hip joint. Arrow indicates the anatomical location of the hip joint. Lower temperatures are observed at 30-days post-treatment 
procedure was conducted after weight-bearing and digital thermography evaluations. On day 0 , the body condition score was determined, according to the Laflamme scale [42].

Normality was assessed with a Shapiro-Wilk test. Mean and maximal values obtained on the dorsoventral view at the initial evaluation and during the follow-up period were compared with those obtained on the lateral view with ANOVA, followed by an LSD post-hoc test, or the Wilcoxon test, as appropriate for the data distribution. Correlations were assessed with the Spearman correlation coefficient. Results were analyzed with IBM SPSS Statistics version 20, $p<0.05$.

\section{Abbreviations \\ CBPI: Canine Brief Pain Inventory; COI: Canine Orthopedic Index; DV: Dorsoventral view; OA: Osteoarthritis; PIS: Pain Interference Score; PSS: Pain Severity Score}

\section{Acknowledgments}

The authors would like to thank Manuel Pereira for the help in preparing this manuscript, Specman, Lda for providing the digital thermography camera, and Concessus and Companion, LiteCure LLC, for providing the Stance Analyser used in this study.

\section{Authors' contributions}

JCA designed the protocol, conducted treatments, and prepared the manuscript. PJ and AS selected patients and conducted treatments. CL and $\mathrm{LMC}$ revised the protocol and prepared the manuscript. All authors have read and approved the manuscript.

\section{Funding}

The authors of this paper do not have any financial or personal relationship with other persons or organizations that could inappropriately influence or bias this paper's content.

\section{Availability of data and materials}

The datasets used and/or analysed during the current study are available from the corresponding author on reasonable request.

\section{Declarations}

\section{Ethics approval and consent to participate}

This study is a part of a project approved by the ethical review committee of the University of Évora (Órgão Responsável pelo Bem-estar dos Animais da Universidade de Évora, approval n GD/32055/2018/P1, September 25th, 2018). Written, informed consent was obtained from the Institution responsible for the animals (Guarda Nacional Republicana, Portuguese Gendarmerie) through dispatch of the Doctrine and Training Commander n³27/16, dated September 16th, 2016

\section{Consent for publication}

Not applicable.

\section{Competing interests}

Companion, LiteCure LLC, provided the Stance Analyser used in this study and the digital thermography camera was supplied by Specman, Lda.

\section{Author details}

'Divisão de Medicina Veterinária, Guarda Nacional Republicana (GNR), Rua Presidente Arriaga, 9, 1200-771 Lisbon, Portugal. ${ }^{2}$ MED - Mediterranean Institute for Agriculture, Environment and Development, Instituto de Investigação e Formação Avançada, Universidade de Évora, Pólo da Mitra, Ap. 94, 7006-554 Évora, Portugal. ${ }^{3}$ Faculty of Veterinary Medicine, University of Lisbon (FMV/ULisboa), Lisbon, Portugal. ${ }^{4}$ Interdisciplinary Centre for Research in Animal Health (CIISA) - University of Lisbon, (FMV/ULisboa), Lisbon, Portugal. ${ }^{5}$ Anjos of Assis Veterinary Medicine Centre (CMVAA), Barreiro, Portugal.
Received: 10 September 2020 Accepted: 11 April 2021

Published online: 01 May 2021

\section{References}

1. Hildebrandt C, Zeilberger K, John Ring EF, Raschner C. The application of medical infrared thermography in sports medicine. In: An International Perspective on Topics in Sports Medicine and Sports Injury. InTech; 2012. https://doi.org/10.5772/28383.

2. Brown J, Henneman K. Imaging in Canine Sports Medicine. In: Zink C, Van Dyke J, editors. Canine Sports Medicine and Rehabilitation. 2nd ed. Hoboken: Wiley Blackwell; 2018. p. 502-19.

3. Vainionpää MH, Raekallio MR, Junnila JJ, Hielm-Björkman AK, Snellman MP, Vainio OM. A comparison of thermographic imaging, physical examination and modified questionnaire as an instrument to assess painful conditions in cats. J Feline Med Surg. 2013;15(2):124-31. https://doi.org/10.1177/1098612 X12463926.

4. Jiang $L$, Ng EYK, Yeo ACB, Wu S, Pan F, Yau WY, et al. A perspective on medical infrared imaging. J Med Eng Technol. 2005;29(6):257-67. https://doi. org/10.1080/03091900512331333158.

5. Marino DJ, Loughin CA. Diagnostic imaging of the canine stifle: a review. Vet Surg. 2010;39(3):284-95. https://doi.org/10.1111/j.1532-950X.2 010.00678.x.

6. Ring EFJ, Ammer K. Infrared thermal imaging in medicine. Physiol Meas. 2012;33(3):R33-46. https://doi.org/10.1088/0967-3334/33/3/R33.

7. Hildebrandt C, Raschner C, Ammer K. An overview of recent application of medical infrared thermography in sports medicine in Austria. Sensors. 2010; 10(5):4700-15. https://doi.org/10.3390/s100504700.

8. Vianna DML, Carrive P. Changes in cutaneous and body temperature during and after conditioned fear to context in the rat. Eur J Neurosci. 2005;21(9): 2505-12. https://doi.org/10.1111/j.1460-9568.2005.04073.x.

9. Varju G. Assessment of hand osteoarthritis: correlation between thermographic and radiographic methods. Rheumatology. 2004;43(7):915-9. https://doi.org/10.1093/rheumatology/keh204.

10. Ring EFJ. The historical development of thermal imaging in medicine. Rheumatology. 2004;43(6):800-2. https://doi.org/10.1093/rheumatology/ keg009.

11. Jin C. Automated analysis method for screening knee osteoarthritis using medical infrared thermography. J Med Biol Eng. 2013;33(5):471. https://doi. org/10.5405/jmbe.1054.

12. Turner TA. Thermography as an aid to the clinical lameness evaluation. Vet Clin North Am Equine Pract. 1991;7(2):311-38. https://doi.org/10.1016/S074 9-0739(17)30502-3

13. Vainionpää $M$, Raekallio $M$, Tuhkalainen $E$, Hänninen $H$, Alhopuro $N$, Savolainen $M$, et al. Comparison of three thermal cameras with canine hip area thermographic images. J Vet Med Sci. 2012;74(12):1539-44. http://www.ncbi.nlm.nih.gov/pubmed/22785576. https://doi.org/10.1292/ jvms.12-0180.

14. Loughin CA, Marino DJ. Evaluation of thermographic imaging of the limbs of healthy dogs. Am J Vet Res. 2007;68(10):1064-9. https://doi.org/10.2460/a jvr.68.10.1064.

15. Infernuso T, Loughin CA, Marino DJ, Umbaugh SE, Solt PS. Thermal imaging of Normal and cranial cruciate ligament-deficient stifles in dogs. Vet Surg. 2010;39(4):410-7. https://doi.org/10.1111/j.1532-950X.2010.00677.X.

16. Grossbard BP, Loughin CA, Marino DJ, Marino LJ, Sackman J, Umbaugh SE, et al. Medical infrared imaging (thermography) of type I thoracolumbar disk disease in Chondrodystrophic dogs. Vet Surg. 2014;43(7):869-76. https://doi. org/10.1111/j.1532-950X.2014.12239.x.

17. McGowan L, Loughin CA, Marino DJ, Umbaugh SE, Liu P, Amini M, et al. Medical infrared imaging of Normal and dysplastic elbows in dogs. Vet Surg. 2015:44(7):874-82. https://doi.org/10.1111/vsu.12372.

18. Sung J, Loughin C, Marino D, Leyva F, Dewey C, Umbaugh S, et al. Medical infrared thermal imaging of canine appendicular bone neoplasia. BMC Vet Res. 2019;15(1):430. https://doi.org/10.1186/s12917-019-2180-6.

19. Allan GS. Radiographic signs of joint disease in dogs and cats. In: Thrall DE, editor. Textbook of Veterinary Diagnostic Radiology. 5th ed. St. Louis: Saunders Elsevier; 2007. p. 317-58.

20. Innes JF. Arthritis. In: Tobias KM, Johnson SA, editors. Veterinary surgery: small animal. St. Louis: Elsevier Saunders; 2012. p. 1078-111.

21. Anderson KL, O'Neill DG, Brodbelt DC, Church DB, Meeson RL, Sargan D, et al. Prevalence, duration and risk factors for appendicular osteoarthritis in 
a UK dog population under primary veterinary care. Sci Rep. 2018;8(1):5641. https://doi.org/10.1038/s41598-018-23940-z.

22. Bliss S. Musculoskeletal structure and physiology. In: Zink C, Van Dyke J, editors. Canine sports medicine and rehabilitation. 2nd ed. Hoboken: Wiley; 2018. p. 32-59. https://doi.org/10.1002/9781119380627.ch3.

23. Edwards SHR. Intra-articular drug delivery: the challenge to extend drug residence time within the joint. Vet J. 2011;190(1):15-21. https://doi.org/10.1 016/j.tvjl.2010.09.019.

24. Alves JC, Santos A, Jorge P, Lavrador C, Carreira LM. A report on the use of a single intra-articular administration of autologous platelet therapy in a naturally occurring canine osteoarthritis model - a preliminary study. BMC Musculoskelet Disord. 2020;21 (1):127. https://doi.org/10.1186/s12891-020-3140-9.

25. Zhang W, Moskowitz RW, Nuki G, Abramson S, Altman RD, Arden N, et al. OARSI recommendations for the management of hip and knee osteoarthritis, part II: OARSI evidence-based, expert consensus guidelines. Osteoarthr Cartil. 2008;16(2):137-62. https://doi.org/10.1016/j. joca.2007.12.013.

26. Evans $\mathrm{CH}$. Novel biological approaches to the intra-articular treatment of osteoarthritis. BioDrugs. 2005;19(6):355-62. https://doi.org/10.2165/0006303 0-200519060-00003.

27. van Weeren PR. General anatomy and physiology of joints. In: Joint Disease in the Horse; 2015. p. 1-24.

28. Piel MJ, Kroin JS, Van Wijnen AJ, Kc R, Im HJ. Pain assessment in animal models of osteoarthritis. Gene. 2014;537(2):184-8. https://doi.org/10.1016/j. gene.2013.11.091.

29. Walton B, Cox T, Innes J. 'How do I know my animal got better?' measuring outcomes in small animal orthopaedics. In Pract. 2018;40(2):4250. https://doi.org/10.1136/inp.k647.

30. Lascelles BDX, Brown DC, Maixner W, Mogil JS. Spontaneous painful disease in companion animals can facilitate the development of chronic pain therapies for humans. Osteoarthr Cartil. 2018;26(2):175-83. https://doi.org/1 0.1016/j.joca.2017.11.011.

31. Hercock CA, Pinchbeck G, Giejda A, Clegg PD, Innes JF. Validation of a client-based clinical metrology instrument for the evaluation of canine elbow osteoarthritis. J Small Anim Pract. 2009;50(6):266-71. https://doi.org/1 0.1111/j.1748-5827.2009.00765.x.

32. Walton MB, Cowderoy E, Lascelles D, Innes JF. Evaluation of construct and criterion validity for the 'Liverpool osteoarthritis in dogs' (LOAD) clinical metrology instrument and comparison to two other instruments. PLoS One. 2013;8(3):e58125. https://doi.org/10.1371/journal.pone.0058125.

33. Upchurch DA, Renberg WC, Roush JK, Milliken GA, Weiss ML. Effects of administration of adipose-derived stromal vascular fraction and platelet-rich plasma to dogs with osteoarthritis of the hip joints. Am J Vet Res. 2016; 77(9):940-51. https://doi.org/10.2460/ajvr.77.9.940.

34. Brown DC, Boston RC, Coyne JC, Farrar JT. Ability of the canine brief pain inventory to detect response to treatment in dogs with osteoarthritis. J Am Vet Med Assoc. 2008;233(8):1278-83. http://www.ncbi.nlm.nih.gov/ pubmed/19180716. https://doi.org/10.2460/javma.233.8.1278.

35. Baltzer Wl, Owen R, Bridges J. Survey of Handlers of 158 Police Dogs in New Zealand: Functional Assessment and Canine Orthopedic Index. Front Vet Sci. 2019:1-6. https://doi.org/10.3389/fvets.2019.00085.

36. Brown DC. The canine orthopedic index. Step 1: devising the items. Vet Surg. 2014;43(3):232-40. https://doi.org/10.1111/j.1532-950X.2014.12142.x.

37. Brown DC. The canine orthopedic index. Step 2: psychometric testing. Vet Surg. 2014;43(3):241-6. https://doi.org/10.1111/j.1532-950X.2014.12141.x.

38. Brown DC. The canine orthopedic index. Step 3: responsiveness testing. Vet Surg. 2014;43(3):247-54. https://doi.org/10.1111/j.1532-950X.2014.12162.x.

39. Seibert R, Marcellin-Little DJ, Roe SC, DePuy V, Lascelles BDX. Comparison of body weight distribution, peak vertical force, and vertical impulse as measures of hip joint pain and efficacy of Total hip replacement. Vet Surg. 2012;41(4):443-7. https://doi.org/10.1111/j.1532-950X.2012.00957.x.

40. Lascelles BDX, Roe SC, Smith E, Reynolds L, Markham J, Marcellin-Little D, et al. Evaluation of a pressure walkway system for measurement of vertical limb forces in clinically normal dogs. Am J Vet Res. 2006;67(2):277-82. https://doi.org/10.2460/ajvr.67.2.277.

41. Clough W, Canapp S, Taboada L, Dycus D, Leasure C. Sensitivity and specificity of a weight distribution platform for the detection of objective lameness and orthopaedic disease. Vet Comp Orthop Traumatol. 2018; 31(06):391-5. https://doi.org/10.1055/s-0038-1667063.

42. Laflamme D. Development and validation of a body condition score system for dogs. Canine Pract. 1997;22:10-5.
43. Puckler K, Tellhelm B, Kirberger R. The hip joint and pelvis. In: Kirberger R, McEvoy F, editors. BSAVA Manual of Canine and Feline Musculoskeletal Imaging. Quedgeley: Wiley; 2016. p. 212-231.

44. Smith G, Karbe G, Agnello K, McDonald-Lynch M. Pathogenesis, diagnosis, and control of canine hip dysplasia. In: Tobias K, Johnston S, editors. Veterinary Surgery: Small Animal. 1st edition. Gloucester: Saunders; 2011. p. 824-848.

45. Reid J, Nolan AM, Scott EM. Measuring pain in dogs and cats using structured behavioural observation. Vet J. 2018;236:72-9. https://doi.org/10.1 016/j.tvjl.2018.04.013.

46. Oosterlinck M, Bosmans T, Gasthuys F, Polis I, Van Ryssen B, Dewulf J, et al. Accuracy of pressure plate kinetic asymmetry indices and their correlation with visual gait assessment scores in lame and nonlame dogs. Am J Vet Res. 2011;72(6):820-5. https://doi.org/10.2460/ajvr.72.6.820.

47. Wilson L, Smith B. Canine lameness. In: McGowan CM, Goff L, editors. Animal Physiotherapy: Assessment, Treatment and Rehabilitation of Animals. 2nd edition. Chichester: Wiley; 2016. p. 112-126.

48. Lascelles B, Freire M, Roe S, DePuy V, Smith E, Marcellin-Little D. Evaluation of functional outcome after BFX total hip replacement using a pressure sensitive walkway. Vet Surg. 2010;39(1):71-7. https://doi.org/10.1111/j.1532950X.2009.00607.x.

49. Borojevic N, Darko K, Grazio S, Grubisic F, Antonini S, Nola IA, et al. Thermography of rheumatoid arthritis and osteoarthritis. Period Biol. 2011: 113:445-8.

50. Fokam D, Lehmann C. Clinical assessment of arthritic knee pain by infrared thermography. J Basic Clin Physiol Pharmacol. 2019;30(3). https://doi.org/1 0.1515/jbcpp-2017-0218.

51. Loeser RF, Goldring SR, Scanzello CR, Goldring MB. Osteoarthritis: a disease of the joint as an organ. Arthritis Rheum. 2012;64(6):1697-707. https://doi. org/10.1002/art.34453.

52. Greve L, Dyson SJ. The interrelationship of lameness, saddle slip and back shape in the general sports horse population. Equine Vet J. 2014;46(6):68794. https://doi.org/10.1111/evj.12222.

53. McKee M. Diagnosis and management of chronic joint pain in the dog. In Pract. 2013;35(5):227-42. https://doi.org/10.1136/inp.f2862.

54. Repac J, Alvarez LX, Lamb K, Gillette RL. Evaluation of Thermographic imaging in canine Hindlimb muscles after 6 min of walking - a pilot study. Front Vet Sci. 2020;7. https://doi.org/10.3389/fvets.2020.00224.

55. Alves JC, Santos AM, Jorge PI. Effect of an Oral joint supplement when compared to Carprofen in the Management of hip Osteoarthritis in working dogs. Top Companion Anim Med. 2017;32(4):126-9. https://doi.org/10.1053/ j.tcam.2017.10.003

56. Alves JC, Santos A, Fernandes Â. Evaluation of the effect of mesotherapy in the management of back pain in police working dogs. Vet Anaesth Analg. 2018;45(1):123-8. https://doi.org/10.1016/j.vaa.2017.07.006.

57. Denoble AE, Hall N, Pieper CF, Kraus VB. Patellar Skin Surface Temperature by Thermography Reflects Knee Osteoarthritis Severity. Clin Med Insights Arthritis Musculoskelet Disord. 2010;3:CMAMD.S5916. https://doi.org/10.413 7/CMAMD.S5916.

58. Warashina H. Clinical, radiographic, and thermographic assessment of osteoarthritis in the knee joints. Ann Rheum Dis. 2002;61(9):852-4. https:// doi.org/10.1136/ard.61.9.852.

59. Powers MY, Biery DN, Lawler DE, Evans RH, Shofer FS, Mayhew P, et al. Use of the caudolateral curvilinear osteophyte as an early marker for future development of osteoarthritis associated with hip dysplasia in dogs. J Am Vet Med Assoc. 2004;225(2):233-7. http://www.ncbi.nlm.nih.gov/pubmed/1 5323379. https://doi.org/10.2460/javma.2004.225.233.

60. Mayhew PD, McKelvie PJ, Biery DN, Shofer FS, Smith GK. Evaluation of a radiographic caudolateral curvilinear osteophyte on the femoral neck and its relationship to degenerative joint disease and distraction index in dogs. J Am Vet Med Assoc. 2002;220(4):472-6. http://www. ncbi.nlm.nih.gov/pubmed/11860241. https://doi.org/10.2460/javma.2 002.220.472.

61. Tôrres RCS, Ferreira PM, Araújo RB, Martins AS. Presença de "Linha Morgan" como indicador de displasia coxofemoral em cães da raça Pastor-Alemão. Arq Bras Med Veterinária e Zootec. 1999;51 (2):157-8. https://doi.org/10.1 590/S0102-09351999000200006.

62. Mehler SJ, May LR, King C, Harris WS, Shah Z. A prospective, randomized, double blind, placebo-controlled evaluation of the effects of eicosapentaenoic acid and docosahexaenoic acid on the clinical signs and erythrocyte membrane polyunsaturated fatty acid concentrations in dogs 
with osteoarthritis. Prostaglandins Leukot Essent Fat Acids. 2016;109:1-7. https://doi.org/10.1016/.jplefa.2016.03.015

63. Moreau M, Lussier B, Pelletier JP, Troncy E. Does a placebo effect really occur in dogs afflicted by hip osteoarthritis as measured by force platform gait analysis? BMC Vet Res. 2013;9:7-10.

64. Innes JF, Fuller CJ, Grover ER, Kelly AL, Burn JF. Randomised, double-blind, placebocontrolled parallel group study of P54FP for the treatment of dogs with osteoarthritis. Vet Rec. 2003;152(15):457-60. https://doi.org/10.1136/vr.1 52.15.457.

65. Volstad N, Sandberg G, Robb S, Budsberg S. The evaluation of limb symmetry indices using ground reaction forces collected with one or two force plates in healthy dogs. Vet Comp Orthop Traumatol. 2017;30(01):54-8. https://doi.org/10.3415/NCOT-16-04-0054.

\section{Publisher's Note}

Springer Nature remains neutral with regard to jurisdictional claims in published maps and institutional affiliations.

Ready to submit your research? Choose BMC and benefit from:

- fast, convenient online submission

- thorough peer review by experienced researchers in your field

- rapid publication on acceptance

- support for research data, including large and complex data types

- gold Open Access which fosters wider collaboration and increased citations

- maximum visibility for your research: over $100 \mathrm{M}$ website views per year

At BMC, research is always in progress.

Learn more biomedcentral.com/submissions 